\title{
SUBDURAL HEMORRHAGES IN INFANTS: CAUSE AND OUTCOME
}

The incidence, cause, and clinical outcome of subdural hemorrhage in children under 2 years of age were evaluated at the Department of Child Health, Bristol, Wales, UK. Of 33 cases identified, 28 were under 1 year of age. The incidence was $12.8 / 100,000$ children/year (21/100,000 for infants under 1 year). Outcome was poor: 9 (27\%) died and 15 (45\%) had severe disability, including blindness in 9, seizures in 8, motor impairment in 7, and hydrocephalus in 5 . Child abuse was subsequently suspected in 27 (82\%), and previous physical abuse is a significant risk factor. In 14 a clear history of shaking was obtained. Only 22 had been adequately investigated. Mandatory evaluations suggested include social assessment, ophthalmologic exam, skeletal survey and bone scan, coagulation screen, and CT or MRI of head. (Jayawant S, Rawlinson A, Gibbon F et al. Subdural haemorrhages in infants: population based study. BMI 5 Dec 1998;317:1558-61). (Respond: Dr S Jayawant, Dept of Child Health, Southmead Hospital, Bristol BS10 5NB, Wales, UK).

COMMENT. Subdural hemorrhage in infants carries a poor prognosis, and child abuse is a major cause. Clinical presentation varies, with only general malaise in some and impaired consciousness in others. One in 5 is admitted to hospital on several occasions because of drowsiness and lethargy, before the diagnosis of subdural hemorrhage is suspected.

\section{HEAD INJURY IN ATTENTION DEFICIT DISORDER PATIENTS}

Characteristics of injuries in 240 children with attention deficit hyperactivity disorder (ADHD) were reviewed retrospectively, using charts submitted to the National Pediatric Trauma Registry, 1988-96, by investigators from Tufts and Harvard Universities, Boston; Children's Memorial Hospital, Chicago; and Johns Hopkins, Baltimore. Compared to controls without ADHD, trauma patients with ADHD sustained head injury more frequently (53\% vs $41 \%$ ), they were admitted to intensive care more frequently (37\% vs $24 \%$ ), and the injury led to disability in $53 \%$ vs $48 \%$. They were more likely to be boys ( $88 \%$ vs $66 \%$ ), and to be injured as pedestrians ( $27 \%$ vs $18 \%$ ) or bicyclists (17\% vs $13 \%$ ). (DiScala C, Lescohier I, Barthel M, Li G. Injuries to children with attention deficit hyperactivity disorder. Pediatrics Dec 1998;102:1415-1421). (Reprints: Carla DiScala PhD, Dept of Physical Medicine and Rehabilitation, Tufts/NEMC, 750 Washington St, Box $75 \mathrm{~K} / \mathrm{R}$, Boston, MA 02111).

COMMENT. Parents of children with ADHD should be counselled about increased risks of injury and use of bicycle helmets. Previous reports have stressed the driving-related risks of ADHD adolescents and young adults and have emphasized the need to prolong stimulant therapy, especially in patients with comorbid oppositional behavior. ADHD patients who continue therapy have no more traffic related accidents than controls. (see Progress in Pediatric Neurology II, PNB Publ, 1994;pp209-210).

\section{ATTENTION DEFICIT DISORDERS}

\section{PRACTICE VARIABLES IN TREATMENT OF ADHD}

The clinical characteristics and treatment methods used for children with ADHD were examined by questionnaires sent to 81 practicing psychiatrists and analyzed at the American Psychiatric Association, Washington, DC. The majority 